\title{
Volumetric and Viscometric studies of solute -solvent and solute-solute interactions of Glycine in aqueous in aqueous electrolytes at $30^{\circ} \mathrm{C}$
}

\author{
Yasmin Akhtar \\ Department of chemistry, University of Tabuk, Tabuk, Saudi Arabia
}

\section{Email address:}

dryasminakhtar2004@yahoo.com

\section{To cite this article:}

Yasmin Akhtar. Volumetric and Viscometric Studies of Solute -Solvent and Solute-Solute Interactions of Glycine in Aqueous in Aqueous Electrolytes at $30^{\circ} \mathrm{C}$. International Journal of Science, Technology and Society. Special Issue: Academic Research for Multidisciplinary. Vol. 3, No. 1-2, 2015, pp. 6-9. doi: 10.11648/j.ijsts.s.2015030102.12

\begin{abstract}
Densities and viscosities of Glycine in aqueous $\mathrm{NaCl}$ and $\mathrm{MgCl}_{2}(0.02 \& 0.06 \mathrm{M})$ solutions have been determined experimentally at $30^{\circ} \mathrm{C}$. The results obtained from density and viscosity measurement have been used to calculate A and $\mathrm{B}$ coefficients and free energies of activation of viscous flow of solvent $\Delta \mu_{1}{ }^{0 \#}$ and solute $\Delta \mu_{2}{ }^{0 \#}$.The results are discussed in terms of the dehydration effect of the electrolytes upon the amino acids and weak solute- solute and strong solute- solvent interactions. The properties of these amino acids in water and water+ electrolytes solution systems are discussed in terms of the charge, size and hydrogen bonding effect.
\end{abstract}

Keywords: Glycine, Aqueous Electrolytes, Jones- Dole coefficients and Free Energies of Activation

\section{Introduction}

Amino acids have zwitter-ion and are the constituents of the most important class of biopolymers, i.e. Proteins .Disarrangement water and electrolyte balance in living systems cause a wide variety of health problems. In physiological media such as blood, membranes, cellulose fluids etc., the dipolar character of amino acids (in presence of ions such as $\mathrm{Na}^{+}, \mathrm{K}^{+}, \mathrm{Mg}^{+2}$ and $\mathrm{Cl}^{-}$etc., dissolved in body water) has an important bearing on their biological functions . Therefore, a knowledge of water-amino acid interaction the effects on several biological processes occurring in living organism(1). The study of interaction between amino acids and electrolytes in aqueous medium, we present in this paper, the study of interaction between aqueous $\mathrm{NaCl}$ and $\mathrm{MgCl}_{2}$ and Glycine at $30^{\circ} \mathrm{C}$. There has been an increased interest in the physicochemical properties of amino acids in aqueous as well as aqueous electrolyte media to understand the role played by the biological molecules in living organism(2-6). In recent years, a number of workers have utilized density and viscosity data to deduce the thermodynamic properties (relative viscosity, Jones -Dole coefficient and free energy of activation of viscous flow) for a number of mixtures solutions (7-9). Structural interactions of non-ionic solutes with ionic ones in different solvents are important in many fields of chemistry and bio-chemistry. Very recently, we have made systematic effort to investigate the ultrasonic and volumetric properties of amino acids in concentrated electrolytic solution (10-12). It was found that $\mathrm{NaCl}$ and $\mathrm{MgCl}_{2}$ increase the apparent molar volume and decrease the adiabatic compressibility of glycine. This increase could be attributed to the interactions of the ions of the $\mathrm{NaCl}$ and $\mathrm{MgCl}_{2}$ electrolytes and zwitter-ion head group of glycine, causing the transfer of hydrated water molecule to the bulk state.

In the present paper, we report densities, $\rho$ and viscosities $\eta$ of Glycine (0.01-0.09 M) in aqueous $\mathrm{NaCl}$ and $\mathrm{MgCl}_{2}(0.02 \&$ $0.06 \mathrm{M})$ solutions have been determined experimentally at $30^{\circ} \mathrm{C}$. From these experimental data a number of thermodynamic parameters namely, Jones- Dole equation to calculate $A$ and $B$ coefficients and free energies of activation of viscous flow of solute and solvent respectively have been calculated. These parameters were utilized to study various interactions taking place in the solutions of glycine in aqueous $\mathrm{NaCl}$ and $\mathrm{MgCl}_{2}$ at $30^{\circ} \mathrm{C}$. 


\section{Experimental}

\subsection{Chemical and Preparation}

Glycine (99.5\% purity), $\mathrm{NaCl}$ and $\mathrm{MgCl}_{2}$ (99.8\% purity) were procured from Merck and S d Fine Ltd. They were used as such without further purification, after drying over calcium chloride in desiccators for more than 48 hours. The viscosities and densities of the amino acids in aqueous electrolytes solution at various concentrations as well as in double distilled de-ionized water were measured experimentally. Aqueous solutions of $\mathrm{NaCl}$ and $\mathrm{MgCl}_{2}$ $(0.02 \& 0.06 M)$ were prepared and these were used as a solvents to prepare glycine solutions on mass basis covering the whole composition range. All the solutions were prepared by mass in dry box and were stored in special air-tight bottles and kept in dark to avoid photo chemical degradation. The weighing was done on an Afcoset ER-120A electronic balance with an accuracy $\pm 0.1 \mathrm{mg}$.

\subsection{Measurement of Density and Viscosity}

The densities were measured with a single capillary pycnometer (made of Borosil glass) of bulb capacity of $8 \times 10^{-}$ ${ }^{6} \mathrm{~m}^{3}$. The marks of the stems were calibrated using double distilled water at $30^{\circ} \mathrm{C}$. The pycnometer was kept for about 30 minutes in a thermostatic water bath so that the thermal fluctuation in density was minimized. The viscosity measurements were carried out by Ubbelohde type suspended level viscometer which was first calibrated with doubled distilled water. The viscometer was allowed to stand in an electronically controlled thermostatic water bath for 30 minutes to minimize the thermal fluctuation. The time of fall was recorded with a stop -watch of least count $0.1 \mathrm{~s}$. At least three time recorded were obtained, and the average value was used as the experimental flow time. Poiseuille's equation was employed to calculate the viscosity of the amino acid + electrolyte + water solutions.

$$
\eta=\frac{\pi \rho h g r 4 t}{8 \mathrm{IV}}=\rho \beta \mathrm{t}
$$

Here $\rho$ is the density of the amino acids solutions, $h$ the height of the column in the viscometer, $g$ is the acceleration due to gravity, $r$ is the radius of the capillary, 1 the length capillary and $t$ is the time of fall of the solution of volume V. The term $\mathrm{h}, \mathrm{g}, \mathrm{r}, \mathrm{l}$ and $\mathrm{V}$ are constant for a given viscometer therefore theses have been replaced by single term $\beta$. The temperature of the water bath was maintained at $30^{\circ} \mathrm{C}$. The viscosity and density data were found to be accurate within \pm $0.1 \%$ and $\pm 0.01 \%$ respectively.

\section{Results and Discussion}

The densities and viscosities of Glycine $(0.02 \& 0.06 \mathrm{M})$ in aqueous $\mathrm{NaCl}$ and $\mathrm{MgCl}_{2}(0.02 \& 0.06 \mathrm{M})$ determined at $30^{\circ} \mathrm{C}$ and are presented in Table 1.It is observed from Table 1 that densities $\rho$ and viscosities $\eta$ for all the ternary systems increase with increase in molarities of glycine. The values of $\rho$ and $\eta$ increase with increase in concentration of amino acids in all the ternary systems under investigation, which appear to be due to hydrophobic properties of solutes i.e.Hbond forming. This may be attributed to the formation of clusters by the amino acids and strong intermolecular forces in the solute. The changes in structure of solvent or solution as a result of $\mathrm{H}$ - bond formation lead to decrease in intermolecular free length (13). Solute may occupy the interstitial spaces in solvent or get solvated forming new weaker bonds. It was suggested (14-16) that what is experimentally observed for any system, reflects the compromise between the tendency for the ion and the peptide to interact with each other and inclination of the solutes to associate with the solvent.

Table 1. Densities ( $\rho$ ) and viscosities ( $\eta$ ) of glycine +aqueous $\mathrm{NaCl}$ and glycine + aqueous $\mathrm{MgCl}_{2}$ at $30^{\circ} \mathrm{C}$

\begin{tabular}{|c|c|c|c|c|}
\hline $\mathrm{C}\left(\mathrm{mol.} \mathbf{l}^{-1}\right)$ & $\rho\left(\mathrm{kg} \mathrm{m}^{-3}\right)$ & $\eta\left(\times 10^{-3} \mathrm{Nm}^{-2} \mathrm{~s}\right)$ & $\rho\left(\mathrm{kg} \mathrm{m}^{-3}\right)$ & $\eta\left(\times 10^{-3} \mathrm{Nm}^{-2} \mathrm{~s}\right)$ \\
\hline & \multicolumn{4}{|c|}{ Glycine + aqueous $+\mathrm{NaCl}$} \\
\hline & \multicolumn{2}{|c|}{$0.02 \mathrm{M}$} & \multicolumn{2}{|c|}{$0.06 \mathrm{M}$} \\
\hline 0.00 & 1020.6 & 0.843 & 1003.8 & 0.862 \\
\hline 0.10 & 1021.3 & 0.847 & 1004.6 & 0.866 \\
\hline 0.30 & 1028.9 & 0.912 & 1007.3 & 0.890 \\
\hline 0.50 & 1031.2 & 0.918 & 1011.8 & 0.913 \\
\hline 0.70 & 1035.7 & 0.931 & 1020.6 & 0.942 \\
\hline \multirow[t]{3}{*}{0.90} & 1041.3 & 0.959 & 1024.7 & 0.967 \\
\hline & \multicolumn{4}{|c|}{ Glycine + aqueous $\mathrm{MgCl}_{2}$} \\
\hline & \multicolumn{2}{|c|}{$0.02 \mathrm{M}$} & \multicolumn{2}{|c|}{$0.06 \mathrm{M}$} \\
\hline 0.00 & 998.7 & 0.825 & 1006.2 & 0.903 \\
\hline 0.10 & 1004.0 & 0.876 & 1006.4 & 0.916 \\
\hline 0.30 & 1013.4 & 0.914 & 1015.7 & 0.960 \\
\hline 0.50 & 1024.9 & 0.991 & 1017.5 & 0.989 \\
\hline 0.70 & 1034.2 & 1.027 & 1020.9 & 1.014 \\
\hline 0.90 & 1038.5 & 1.180 & 1025.3 & 1.062 \\
\hline
\end{tabular}

The viscosity data were used to calculate the relative viscosity using Jones- Dole equation [17]

$$
\eta_{\mathrm{rel}}=\eta / \eta_{\mathrm{o}}=\left[1+\mathrm{AC}^{1 / 2}+\mathrm{BC}\right]
$$

Where, $\eta$ and $\eta_{\mathrm{o}}$ viscosities of the solutions and solvent respectively. B, is the Jones- Dole coefficient [17], an empirical constant, and is measure of ion-solvent interaction. Its values depend on the size and shape of the solute particles. The A is the Falkenhagen coefficient [18] which indicates ion-pair electrostatic interactions. They were obtained by a least square treatment as the intercepts and slopes of the linear plots of $\eta / \eta_{\mathrm{o}^{-}}-1 / \mathrm{C}^{1 / 2}$ versus $C^{1 / 2}$ and their values are given in Table 2 . 
Table 2. Falkenhagen coefficient, (A), Jones Dole coefficient, (B), Free energy of activation per mole of solvent, $\left(\Delta \mu_{1}^{0 \#}\right)$ and solute $\left(\Delta \mu_{2}^{0 \#}\right)$ of Glycine + aqueous $\mathrm{NaCl}$ and Glycine + aqueous $\mathrm{MgCl}_{2}$ at $30^{\circ} \mathrm{C}$

\begin{tabular}{|c|c|c|c|c|}
\hline $\mathrm{C}\left(\mathrm{mol} \mathrm{I}^{-1}\right)$ & $\begin{array}{c}\mathrm{A}\left(10^{-2} \mathrm{dm}^{3 / 2}\right. \\
\left.\mathrm{mol}^{-1 / 2}\right)\end{array}$ & $\begin{array}{c}\text { B }\left(\mathbf{1 0}^{-1} \mathbf{d m}^{3}\right. \\
\left.\mathrm{mol}^{-1}\right)\end{array}$ & $\begin{array}{c}\Delta \mu_{1}^{0 \#} \\
\left(\mathrm{KJ} \mathrm{mol}^{-1}\right)\end{array}$ & $\begin{array}{c}\Delta \mu_{2}{ }^{0 \#} \\
\left(\mathrm{KJ} \mathrm{mol}^{-1}\right)\end{array}$ \\
\hline & \multicolumn{4}{|c|}{ Glycine + water } \\
\hline & \multicolumn{4}{|c|}{$\mathrm{NaCl}$} \\
\hline 0.02 & 5.926 & 0.958 & 9.12 & 28.39 \\
\hline \multirow{2}{*}{0.06} & -4.726 & 1.858 & 9.22 & 41.86 \\
\hline & \multicolumn{4}{|c|}{$\begin{array}{c}\text { Glycine + water } \\
\mathrm{MgCl}_{2}\end{array}$} \\
\hline 0.02 & -6.290 & 4.302 & 9.22 & 37.85 \\
\hline 0.06 & -0.320 & 1.950 & 9.13 & 72.34 \\
\hline
\end{tabular}

The viscosity, $\eta$, of dilute solution of non-electrolytes is represented by

$$
\eta=\eta_{0}(1+B C)
$$

For a dilute solution of unsolvated spherical colloidal suspension, has derived by Einstein relation

$$
\eta_{\mathrm{rel}}=1+2.5 \varphi
$$

Where $\varphi$ is the volume fraction of the solute. If this equation is valid or amino acids, Eq. (3) becomes

$$
\eta_{\mathrm{rel}}=1+0.0025 \mathrm{~V}_{\mathrm{h}} \mathrm{C}
$$

Where $\mathrm{V}_{\mathrm{h}}$ is the hydrodynamic volume, since $\mathrm{AC}^{1 / 2}$ term in Eq. 2 can be assumed to be negligible in a dilute solution, the following relation holds

$$
\mathrm{B}=0.0025 \mathrm{~V}_{\mathrm{h}}
$$

Hakinet.al[19] may be assumed that the partial molar volume at infinite dilution of the unsolvated solute particle in a continuum solvent. The more $\mathrm{B}$ values in the mixed solvent might mean a more hydrodynamic volume in the mixed solvent.

A perusal of Table 2 shows that the values of A coefficients are negative and those of B coefficients are large positive for all the ternary systems under investigation, thereby suggesting the ion-ion interactions are weak and ion-solvent interactions are strong. The positive value of $\mathrm{B}$ with electrolytes concentration of water molecules as a result of shielding of polar terminal groups of glycine molecules is due to increased interaction between these polar ends and ions of the electrolytes. They have estimated the contraction of water around the appositively charged group is caused by electrostatic ion- solvent interaction and is called as electrostriction. A mutual comparison of the $\mathrm{NaCl}$ and $\mathrm{MgCl}_{2}$ shows that values of $\mathrm{A}$ and $\mathrm{B}$ are larger in case of $\mathrm{MgCl}_{2}$ than $\mathrm{NaCl} . \mathrm{Mg}^{+2}$ ions being smaller in size, has an intense force field and hence a strong hydration co sphere around it. Therefore hydration of $\mathrm{MgCl}_{2}$ ( ion-solvent ) will be much more than that of $\mathrm{NaCl}$. Further to this effect is superimposed the effect of interaction of cations $\left(\mathrm{Na}^{+}\right.$and $\left.\mathrm{Mg}^{+2}\right)$ and anion $\left(\mathrm{Cl}^{-}\right)$with negative and positive charge centers of glycine respectively (ion-ion interaction). The double charge on $\mathrm{Mg}^{+2}$ ion results in intense electric field and thus, the possibility of interactions with glycine is larger in case of glycine with aqueous $\mathrm{MgCl}_{2}$ ternary system. The hydration behavior of amino acids considered the following interactions (a) Akhtar[4] as the terminal groups of zwitter-ions of amino nature which may hydrophobic, hydrophilic or amphiphilic, acids, $-\mathrm{NH}_{3}{ }^{+}$and $\mathrm{COO}^{-}$are hydrated in electrostatic manner whereas hydration of intervening backbone depends on its, (b) the overlap of hydration groups co spheres of terminal ($\mathrm{NH}_{3}{ }^{+}$and $\mathrm{COO}^{-}$) and the adjacent groups result in volume change . (c) Electrostriction of $\mathrm{NH}_{3}{ }^{+}$group is greater than the $\mathrm{COO}^{-}$by a factor of 10 . Table 2 shows that the values of $\mathrm{B}$ are positive which indicates strong solute-solvent interactions.

According to the transition state theory of the relative viscosities of electrolytic solutions proposed by Feakins et al (20), the B- coefficient given as

$$
\mathrm{B}=\left(\overline{\mathrm{V}}_{1}^{0}-\overline{\mathrm{V}}_{2}^{0}\right) / 1000+\overline{\mathrm{V}}_{1}^{0}\left[\left(\Delta \mu_{2}{ }^{0 \#}-\Delta \mu_{1}^{0 \#}\right) / \mathrm{RT}\right]
$$

Where $\overline{\mathrm{V}}_{1}{ }^{0}$-and $\overline{\mathrm{V}}_{2}{ }^{0}$ are the partial molar volumes of the solvent and solute at infinite dilution, respectively , $\Delta \mu_{1}{ }^{0 \#}$ the free energy of activation per mole of the solvent and $\Delta$ $\mu_{2}{ }^{0 \#}$ is the free energy of activation per mole of the solute . The $\Delta \mu_{1}{ }^{0 \#}$ and $\Delta \mu_{2}{ }^{0 \#}$ were calculated from the equation

$$
\Delta \mu_{1}{ }^{0 \#}=\mathrm{RT} \ln \left(\eta^{0} \overline{\mathrm{V}}_{1}^{0} / \mathrm{hN}_{\mathrm{A}}\right)
$$

and

$$
\Delta \mu_{2}{ }^{0 \#}=\Delta \mu_{1}{ }^{0 \#}+\mathrm{RT} / \overline{\mathrm{V}}_{1}^{0}\left[1000 \mathrm{~B}-\left(\overline{\mathrm{V}}_{1}^{0}-\overline{\mathrm{V}}_{2}^{0}\right)\right]
$$

Where $\mathrm{R}, \mathrm{h}$ and $\mathrm{N}$ are the gas constant, Planck's constant and constant respectively and $\mathrm{T}$ are the absolute temperature. The values of $\Delta \mu_{1}{ }^{0 \#}$ and $\Delta \mu_{2}{ }^{0 \#}$ for different compositions of glycine in aqueous $\mathrm{NaCl} / \mathrm{MgCl}_{2}$ are given in Table 2 . Table 2 shows that $\Delta \mu_{2}{ }^{0 \#}$ are larger than $\Delta \mu_{1}{ }^{0 \#}$ suggesting that the formation of transition state is accompanied by the breaking and distortion of the intermolecular bonds. Moreover, the greater values of $\Delta \mu_{2}{ }^{0 \#}$ than $\Delta \mu_{1}{ }^{0 \#}$ suggest that the metal chlorides under study, behave as structure makers/promoters in different concentration ranges of glycine. Greater values of $\Delta \mu_{1}{ }^{0 \#}$ have also been reported in mixtures of sucrose solution(21).

A comparison of $\Delta \mu_{1}{ }^{0 \#}$ and $\Delta \mu_{2}{ }^{0 \#}$ values of the two solutes result the structure making ability of $\mathrm{Mg}^{+2}$ is greater than $\mathrm{Na}^{+}$ which may be due to stronger solute-solvents interaction in $\mathrm{MgCl}_{2}$ solutions. Therefore the hydration of $\mathrm{MgCl}_{2}$ will is much more than that of $\mathrm{NaCl}$. The double charge on $\mathrm{Mg}^{+2}$ results in intense electric field and the radius of $\mathrm{Mg}^{+2}$ is much smaller than the $\mathrm{Na}^{+}$thus the possibility of interactions with glycine is larger in case of glycine + aq $\mathrm{MgCl}_{2}$ ternary systems. The greater values of $\Delta \mu_{2}{ }^{0 \#}$ at $0.06 \mathrm{M}$ concentration for both the electrolytes which indicates the maximum structure making ability. Increase in concentrations of electrolytes from $0.02 \& 0.06 \mathrm{M}$ probably causes disruption of the intermolecular bonds of the solvent, thereby decreasing the values of $\Delta \mu_{2}{ }^{0 \#}$.

Thus the trends and magnitude of the various parameters obtained from viscosity measurement reported in this paper. The studies suggest that ion- solvent interactions are stronger 
and ion-ion interactions are weak . The extent of interactions and structure making ability is greater in case of $\mathrm{MgCl}_{2}$. The $\mathrm{dB} / \mathrm{dT}$ is a better criterion for determining the structure making/ breaking nature of any electrolyte rather than simply the B- coefficient.

\section{Acknowledgement}

I am highly thankful to Dr. Tanveer A. Department of Chemistry, University of Tabuk, K.S.A for their co-operation and valuable suggestions.

\section{References}

[1] Y. Akhtar, "Volumetric and viscometric behavior of amino acids in aqueous metal electrolytes solutions at $308 \mathrm{~K}$,,Fluid Phase Equil. Vol. 2582007 pp125-131.

[2] Y. Akhtar, J. international acad. Res. Multi Disipliry. , "Molecular and thermodynamic interactionstudies of $\mathrm{D}(+)$ glucose with mixed solvents of electrolytes solutions at 303K", vol. 22014 pp 693-700.

[3] F. J. Millero, A. L. Surdo and C. Shiv,“Apparent molal volumes and adiabatic compressiblities of aqueous transition metals.” J. Phys. Com. Vol. 841980 pp719-723.

[4] S. S. Aswale, S.R. Aswalev and and R. S. Hajare,"Adiabatic compressibility intermolecular free length and acoustic relaxation time of aqueous antibiotic cefotaxime sodium" Indian J. Chem., vol.4 2012 pp2671-2677.

[5] S. Thirumaran and J. K. Sabu, "Ultrasonic studies of interactions of some alkali halides in aqueous d-glucose solutions at varying molalities and temperature", Journal Exp. Sci., Vol. 32012 pp33-39.

[6] M. J. Iqbal and M. A. Chaudhry, "Volumetric and viscometric studies of drugs in aqueous medium at different temperature", J. Chem. Engg. Vol. 542009 pp 2772-2776.

[7] A. K. Nain and R. Pal. " Study of solute- solute and solute solvent interactions of Threonine in aqueous glucose solutions at different temperatures by using volumetric andviscometric methods", J. ChemThermodyn., vol.104 2013; pp 60-98.

[8] E. J Gonzalez, S. B. Bottini, S. Peeda and E. A. Macedo, "Liquid- Liquid equlibria of binary systems, Experimental data and Thermodynamic modeling using a group contribution equation of state" Fluid Phase Equil. Vol.362 2014 pp163-169.

[9] M. J. Iqbal and M. Siddiquah, " Partial molar volume of mefenamic acid in alcohol at temperature 293.15 and 313.15 K," J. Braz. Chem. Soc. Vol.17 2006 pp727-735.

[10] F. Ciotta, J. P. M. Truster and V. Vesovic, " Extended hard sphere model for the viscosity", Fluid Phase Equilib. Vol.363 2014 pp239-247.

[11] X. Jiang, C. Zhu and Y. Ma."Volumetric and viscometric studies of amino acids in L-L-ascorbic acid aqueous solutions at temperature 293.15- 323.15 K", J. Chem. Thermodyn. Vol.71 2014 pp50-63..

[12] Y. Akhtar, S. F. Ibrahim, Arabian, "Ultrasonic and thermodynamic studies of glycine in aqueous electrolytes solutions at 303 K", J. Arabian Chem. Vol. 42011 pp 487- 490.

[13] R. K. Wadi and P. Ramasmi "Partialmolal volumes and adiabatic compressibility of transfer of glycine and D-L alanine from water to aqueous sodium sulphate at 288.15, 298.15 and 308.15 K”, J. Chem. Soc. Faraday Trans. Vol. 93 1997 243-247.

[14] M. S. Hussain, T. K. Biswas, D. C. Kabiraz, M. N. Islam and M. E. Haque, "Studies on sodium dodecylsulphate in aqueous and in aqueous amino acids solutions", J. Chem. Thermodyn. Vol.71 2014; pp6-13.

[15] I.L. Shulgin and E. Ruckenstein“ Relationship between preferential interac- tion of a protein in an aqueous mixed solvent and its solubility",Biophys Chem. Vol. 1182005 pp128-34.

[16] Vishnu D., Y. Akhtar, J. D.Pandey, "Ultrasonic and Thermodynamic studies of Ternary solutions",ActaAcoust. , Vol 841998 pp 976981.

[17] G. Jones and M. Dole," The viscosity of aqueous solutions of strong with special reference to barium chloride " J. Am. Chem. Soc. Vol. 511929 pp 2950-2964.

[18] H. Fakenhagen and E. L. Vernon ,"The viscosity of aqueous solutions of strong electrolytes solutions according to electrostatic theory" ,Phil. Mag. Vol.14(92) 1932 pp 537-565.

[19] A. W. Hakin, M. M. Duck, J. L. Marty, K. E. Preuss, J. Chem. Soc. Faraday Trans. 90 (1994)2027-2037.

[20] D. Feakins, D. J. Freemantle, K. G. Lawrence, " transition state treatment of the relative viscosity of electrolytes solutions ", J. Chem. Soc. Faraday Trans. I, Vol. 701974 pp 795-806.

[21] S. C. Bai, G. B. Yan , "Viscosity B-coeffecients and activation parameters for viscous flow of sucrose solution", Carbohydrates Research, Vol. 3382003 pp 2921-2927. 